\title{
Influence of plasma treatment on wettability and scratch resistance of Ag-coated polymer substrates
}

\author{
Damian WojcieszaK ${ }^{1}$, Agata Poniedziatek ${ }^{1 *}$, MichaŁ Mazur ${ }^{1}$, JarosŁaW \\ DOMARADZKI $^{1}$, DANUTA KACZMAREK ${ }^{1}$, JERZY DORA ${ }^{2}$ \\ ${ }^{1}$ Faculty of Microsystem Electronics and Photonics, Wroclaw University of Technology, Janiszewskiego 11/17, \\ 50-372 Wroclaw, Poland \\ ${ }^{2}$ DORA Power System, Wilczycka 8, 51-361 Wroclaw, Poland
}

\begin{abstract}
Rapid progress in thin-film coatings based on metals, which can be deposited on polymers, has been recently observed. In this work discussion on the properties of modified polymers and silver thin films deposited on polytetrafluoroethylene (PTFE) and polycarbonate (PC) substrates has been presented. Surface of these polymer substrates were exposed to argon plasma discharge. Additionally, silver thin films were deposited on their surface by electron beam evaporation method. The surfaces of the modified polymers were studied by different methods, i.e. topography, wettability and scratch resistance measurements were performed. The ageing effect of treated substrates was also discussed. It was shown that plasma modification of PTFE and PC substrates increased wettability of their surfaces. The value of water contact angle decreased of about $40 \%$ and $25 \%$ for PTFE and PC surface, respectively. The change of hydrophobic to hydrophilic properties was observed. Plasma modification of substrates improved adhesion between silver coating and polymer substrates. However, it did not influence wettability of Ag coating.
\end{abstract}

Keywords: thin film; plasma modification; polymers; wettability; electron beam evaporation; scratch resistance

(C) Wroclaw University of Technology.

\section{Introduction}

Development in science and technology is relevant with the production of innovative materials with their specific properties depending on application. Polymers with precisely defined properties play an increasingly important role in the development of modern technology. Especially, the growing interest in thin film coatings deposited on various polymers has been observed. Polymers are frequently used in different application fields, such as biomaterials, adhesive and protective coatings, microelectronic devices, thin-film technology and many others, due to their excellent physical and chemical properties [1-7]. Polymers are easy to manufacture and they are characterized by low density, flexibility and cost-effectiveness [8].

Desired surface properties of polymers such as hydrophilicity, roughness, crystallinity

*E-mail: agata.poniedzialek@pwr.edu.pl or conductivity are required for their successful application [2, 3]. On the other hand, they are often unsuitable to use due to their low surface energy leading to poor wettability, adhesion, printability and scratch-resistance [1, 8, 9]. For these reasons, surface of polymer should be somehow activated to change its properties $[1-3,8,10]$. According to Pelagade et al. [11] surface modification techniques of polymers can be divided into three categories such as: (1) cleaning or etching material from the surface, (2) surface reactions that create functional groups and cross linking and (3) deposition of thin films. The common methods of surface modification include mechanical, chemical or physical treatments. The most frequently used treatments are, e.g.: flame, corona discharge, plasma, photons, electrons, ion beam or $\mathrm{X}$-rays $[2,3,12,13]$. These methods are used to achieve changes of polymer such as formation of special functional groups at the surface, increase of surface energy, change of wettability, improvement 
of chemical inertness and dyeability, introduction of surface cross linking, removal of weak boundary layers or contaminants, modification of surface morphology or improvement of surface electrical conductivity $[3,8,11,13,14]$.

According to Chan et al. [3] plasma treatment is probably the most versatile surface treatment technique. Plasma, sometimes called the fourth state of matter, has been known for a very long time. Plasma can be defined as a partly or fully ionized gas containing charged and neutral particles, e.g. electrons, positive and negative ions, molecules, radicals and atoms [3, 15-17]. In recent years, the use of plasma treatment of polymers for modification of their surface properties has been studied as an environmentally friendly alternative to the wet chemical techniques $[1,11,15,18]$. This kind of surface modification has many advantages, including modification of just the outermost atomic layers of the substrate, reduction of thermal degradation and modification without affecting the bulk properties of the polymer [18-21]. Plasma surface modification is used to create new chemical groups on their surface, branching and cross linking of macromolecules and formation of low molecular weight oxidized structures $[2,11,12,15,19,22]$. Appearance of polar groups on the polymer surface leads to a change in wetting behavior, thus, strengthening the hydrophilicity of treated materials [23]. However, the surface roughness is also affected by the plasma treatment that can also change its wettability $[20,24]$. Surface properties of plasma treated polymers depend on, e.g., gases composition, exposure time, frequency and plasma power [8, 12, 13]. Polymers are often modified using noble gas $(\mathrm{He}$, $\mathrm{Ne}$, and $\mathrm{Ar})$ or reactive gas $\left(\mathrm{O}_{2}\right)$ plasma $[25,26]$. In general, reaction of plasma with a polymer surface can be divided into three groups: surface reactions, which lead to functional groups production, plasma polymerization, cleaning and etching [3]. Oxygen or nitrogen plasma treatment leads to implementation of polar functional groups on the polymer surface. The consequences of these processes are improvement of adhesion properties, bonding of polymers and hydrophilization of their surface $[10,15,20,27]$. One of the most valid disadvantage of plasma treatment is the ageing effect. Functional polar groups formed on the treated surface are not stable in time, as the surface tends to recover to its previous state [10, 20, 22]. Surface ageing is characterized by two processes. The first one is the reorientation of the polar groups into the bulk polymer and the second is the mobility of small polymer chain segments into the matrix [10]. Thus, the results of these processes are a decrease in surface energy and a significant decrease of surface wettability $[8,10,12,13,24]$.

Metallic films on polymer surface are important components in the microelectronic circuits, optical and mechanical devices, in the construction of diodes, CD's; they also find application in medicine [13]. As mentioned, polymers are characterized by low surface energy and poor adhesive properties. Therefore, to ensure good adhesion between polymer and metal, the surface of polymer must be activated by, e.g., plasma treatment $[10,12,13,15]$. Deposition of metallic thin film on polymer substrates can be performed using various physical and chemical processes [13]. Among these techniques we can distinguish electroless plating of polymers in solutions of metallic salts, electroforming, thermal spraying, magnetron sputtering and electron beam evaporation [13, 28].

In this paper, the properties of plasma treated polymers (polycarbonate and polytetrafluoroethylene) and metallic coatings deposited on their surface by electron beam evaporation have been described.

\section{Experimental}

PTFE (from DuPont) and PC foils (from SABIC Innovative Plastics) were used as substrates for the investigations. PTFE and PC had thicknesses of $250 \mu \mathrm{m}$ and $1 \mathrm{~mm}$, respectively, and their size was equal to $100 \mathrm{~mm} \times 100 \mathrm{~mm}$. Plasma treatment was performed in a cylindrical discharge chamber with an argon gas. The working chamber was initially pumped to ca. $2 \mathrm{~Pa}$. Next, argon was dosed and its flow was set in order to obtain ca. $17 \mathrm{~Pa}$ pressure in the chamber. Samples were treated for $60 \mathrm{~s}$ with different power regulated 
using pulse width modulation (PWM) method with the PWM fill factor equal to: $10 \%, 30 \%$ and $50 \%$. Maximum plasma power in the applied reactor with $100 \%$ PWM coefficient was $500 \mathrm{~W}$. The distance between electrodes was $12 \mathrm{~mm}$.

After surface modification of polymers silver thin films were deposited by electron beam evaporation method. During the deposition, Ag pellets $(99.999 \%)$ were melted by electron beam and evaporated from a tungsten boat. During the process, the pressure was kept below $3 \times 10^{-3} \mathrm{~Pa}$. Thin films were deposited with a rate of ca. $3.3 \AA / \mathrm{s}$ and their thickness was equal to $50 \mathrm{~nm}$. During evaporation of silver thin films the power was equal to ca. $60 \mathrm{~W}$. The voltage of the ion gun was $6 \mathrm{kV}$, while the current was $10 \mathrm{~mA}$.

Immediately after plasma treatment the surface properties of polymers and thin films deposited on modified samples were analyzed by contact angle measurement. Surface wettability was assessed by a Theta Lite tensiometer (Attension). Liquid used for the contact angle determination was deionized water with a conductivity of $0.05 \mu \mathrm{S} / \mathrm{cm}$. Contact angle measurements were performed according to the sessile drop method $[29,30]$.

Roughness of the modified polymers and thin films was determined with the aid of CCI Theta Lite optical profiler (Taylor Hobson). The surface diversification of polymers was examined by the value of root mean square roughness $(\mathrm{Sq})$ and average roughness $(\mathrm{Sa})$. Scratch resistance of $\mathrm{Ag}$ thin films deposited on unmodified and modified substrates was investigated using a Summers Optical's Lens Coating Hardness Test Kit. For this purpose the abrasion test consisting in rubbing the surface of $\mathrm{Ag}$ coating with a cotton fabric pad for 50 cycles using applied load of $0.5 \mathrm{~N}$ was performed according to the well acknowledged standard [31, 32]. Thin film surface was examined for scratch resistance by optical microscope (Olympus BX51) while the change of roughness after scratch test of $\mathrm{Ag}$ thin films deposited on polymer substrates was evaluated by optical profiler (Taylor Hobson CCI Lite).

\section{Results and discussion}

\subsection{Surface properties of plasma treated PTFE and PC substrates}

The surface diversification of plasma treated polymers was examined by optical profiler. Performed investigations showed that the surface of untreated PTFE foil was smoother than in case of samples treated for $60 \mathrm{~s}$ with $10 \%$ PWM (Fig. 1a). The value of Sq parameter for untreated PTFE was equal to $0.67 \mu \mathrm{m}$, while for plasma treated substrates it was $0.70 \mu \mathrm{m}$. According to Sarani et al. [33] PTFE surface also showed an increased roughness due to plasma etching reactions, which could in turn lead to higher contact angle values. As shown in Fig. 1b plasma treatment did not change significantly the PC surface diversification. Plasma modification of PC substrates carried out with various PWM coefficients changed their roughness slightly of ca. $0.5 \mathrm{~nm}$ as-compared to unmodified PC. It is worth mentioning that the roughness of PTFE surface was almost three orders higher than that of PC surface. The results showed that plasma treatment did not significantly change surface diversification and value of $\mathrm{Sq}$ of the polymers.

Contact angle measurements showed that argon plasma treatment with different discharge power changed the surface wettability of measured polymers. The images of droplets at the surface of PTFE and PC are presented in Fig. 2. The unmodified PTFE substrate had hydrophobic surface and the value of contact angle was equal to $108^{\circ}$. After plasma treatment with $10 \%, 30 \%$ and $50 \%$ of PWM coefficient, the water contact angle of PTFE decreased to ca. $72^{\circ}, 63^{\circ}$ and $65^{\circ}$, respectively. This change might be caused by the creation of polar groups that exhibited enhanced hydrophilicity at the polymer surface, as it was previously shown by others $[12,33,34]$. In turn, in case of PC substrate, the change of its wettability was slightly less distinct. In particular, the contact angle decreased gradually from $94^{\circ}$ for untreated substrate to $69^{\circ}$ for PC treated with $50 \%$ plasma power. After modification of both polymers their water contact angle was below $80^{\circ}$. The decrease of water contact angle 
(a)

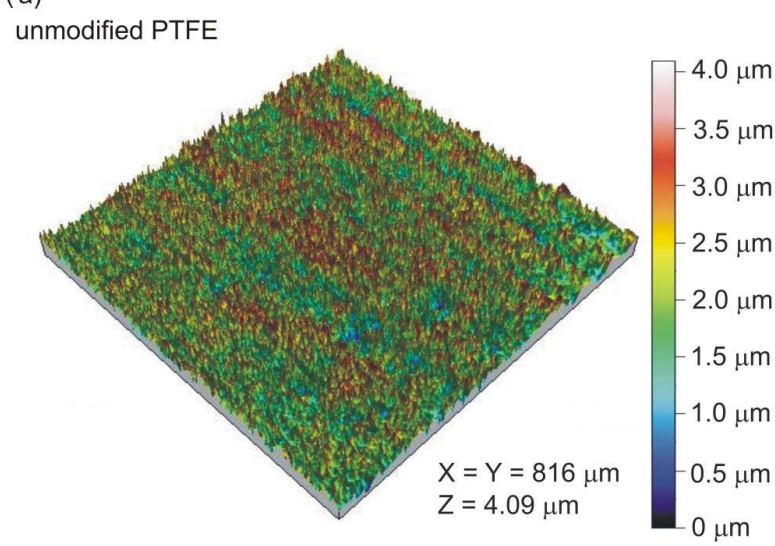

(b)

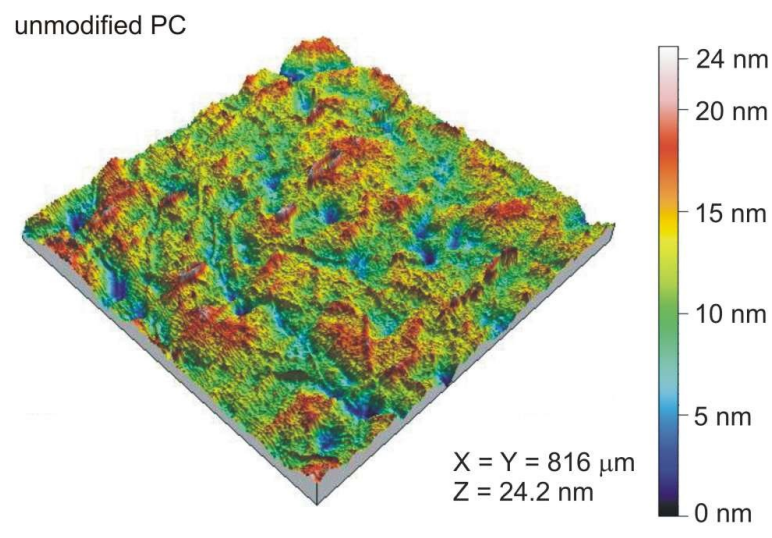

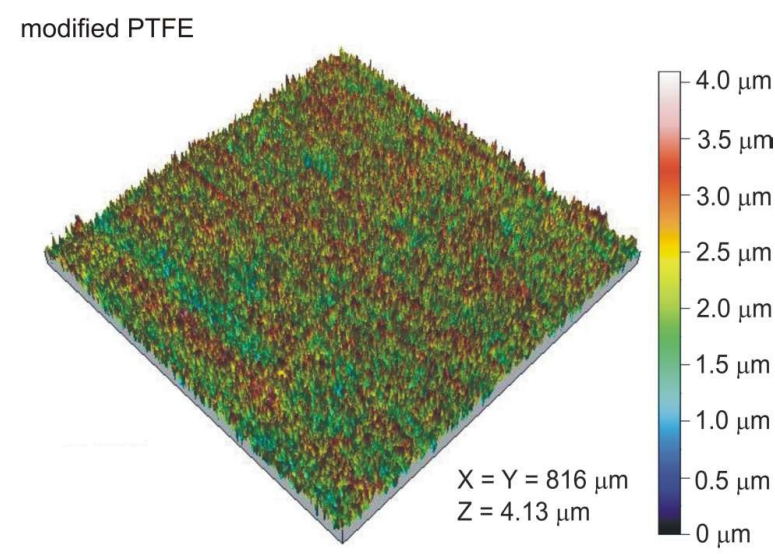

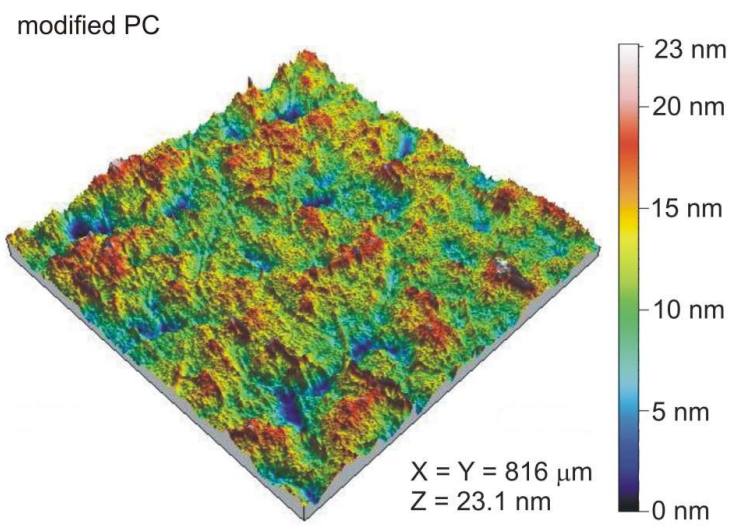

Fig. 1. Three dimensional surface images of unmodified and modified: (a) PTFE and (b) PC substrates.

was observed for all plasma treatments with various PWM coefficients.

According to Trepilowski et al. [26] the increased hydrophilicity of activated polycarbonate surface has been also observed. This effect may be caused by mechanical etching of the surface, which leads to increased roughness and appearance of free electron pairs on the surface. The polar component of the apparent surface free energy is significant. In consequence, Trepilowski et al. [26] stated that this effect was more pronounced for longer exposition time of PC surface to argon plasma. Very similar results were obtained by Pelagade et al. [11].

The ageing effect was measured for PTFE and PC substrates treated for $60 \mathrm{~s}$ in argon plasma with $10 \%$ PWM. The contact angle was measured immediately and several days after the plasma treatment. Results of ageing effect for PTFE and PC are presented in Fig. 3. The hydrophillic effect of the PTFE and PC surfaces obtained after plasma treatment, maintained for at least 14 days. After two weeks the value of contact angle for the modified PTFE and PC remained almost intact and was equal to ca. $73^{\circ}$ and $77^{\circ}$, respectively.

\subsection{Surface properties of Ag coatings de- posited on plasma treated $\mathrm{PC}$ and PTFE substrates}

Metallic coatings deposited on plasma treated PTFE and PC surface were examined by optical profiler. The analysis of three-dimensional profiles showed that the roughness value of Ag thin films deposited on modified PTFE surface at different powers as compared to unmodified PTFE surface decreased of about $13 \%$ (Fig. 4a). In case of Ag coating deposited on PTFE substrate treated with 


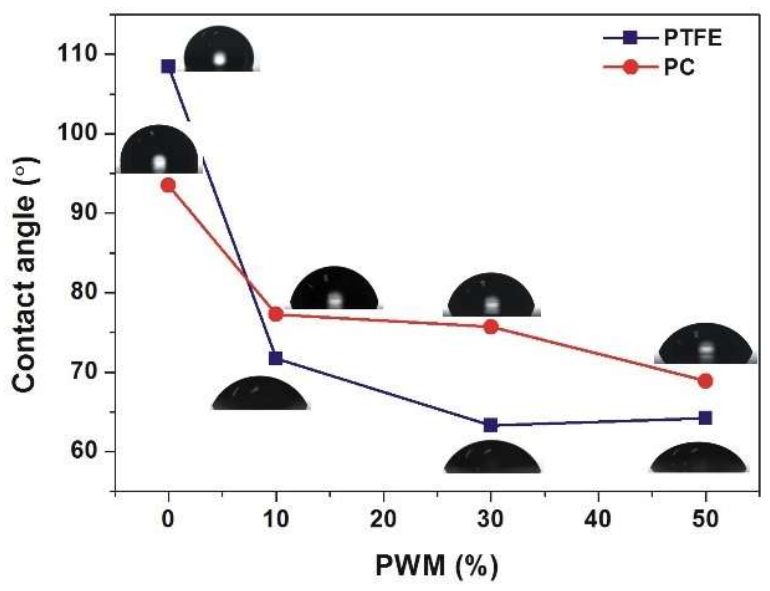

Fig. 2. Results of water contact angle measurements of PTFE and PC substrates in the function of PWM coefficient.

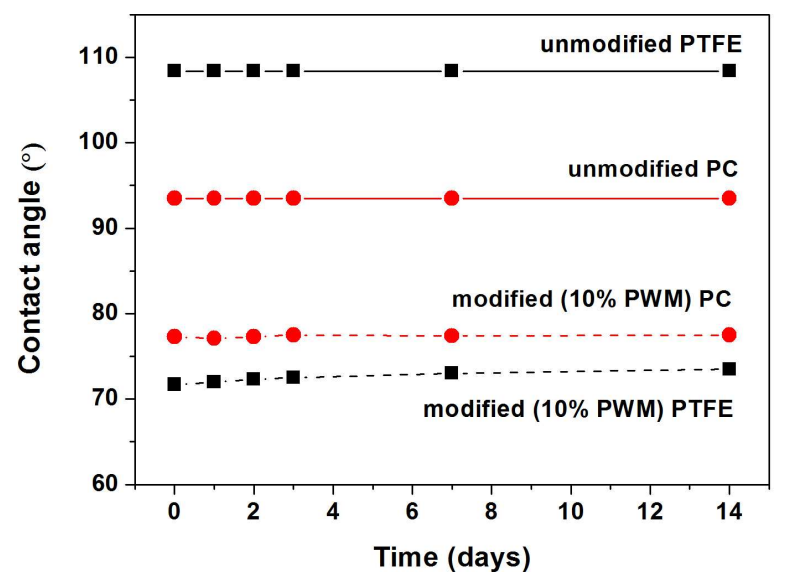

Fig. 3. Results of contact angle measurements in the function of time.

plasma discharge of $30 \%$ of PWM, the root mean square roughness was equal to $0.66 \mu \mathrm{m}$. However, further PWM increase to $50 \%$ resulted in the simultaneous increase of the surface diversification, which in turn reached the value of roughness of the unmodified PTFE surface.

The analysis of PC surface profiles with $\mathrm{Ag}$ coatings showed only slight changes (Fig. 4b). After the deposition of $\mathrm{Ag}$ thin films on unmodified and modified PC surface, the decrease of surface roughness from $4.0 \mathrm{~nm}$ to $2.9 \mathrm{~nm}$ with the increase of plasma discharge PWM coefficient was observed.
There was only a negligible change of wettability of Ag coating treated with argon plasma with various PWM coefficients. The contact angle for $\mathrm{Ag}$ thin films deposited on PTFE and PC substrates was in the range of ca. $81^{\circ}$ to $86^{\circ}$ and it was rather independent of PWM coefficient (Fig. 5).

\subsection{Scratch resistance of Ag coatings de- posited on unmodified and plasma treated PTFE and PC substrates}

In case of $\mathrm{Ag}$ coatings deposited on the plasma treated surface of PTFE and PC their scratch resistance is one of the most important properties. For this reason abrasion resistance test was carried out. The measurements were conducted with the aid of optical microscope working in reflected light mode. Therefore, bright areas in the image represent the Ag thin film deposited on PTFE or PC substrate, while the dark areas are simply polymers surface without Ag coating, which was scratched off during the abrasion test. The three-dimensional profiles from profiler and images from optical microscope (Fig. 6) showed that the unmodified surface of PTFE with Ag coating had worse scratch resistance than Ag coatings deposited on polymer after argon plasma treatment. The value of root mean square roughness $(\mathrm{Sq})$ decreased of ca. $5 \%$ after the scratch test. Analysis of obtained images performed with an Olympus Stream Essentials 1.7 software showed that the percentage of scratched off Ag coating deposited on unmodified PTFE was two times larger as compared to the metallic coating deposited on modified substrates. It was $60.9 \%$ and $30.1 \%$ for unmodified and modified PTFE, respectively.

The results obtained after 50 cycles of scratch test for unmodified and modified PC with Ag thin film are similar to the results obtained for PTFE (Fig. 7). After the scratch test, the roughness of unmodified PC substrate with deposited Ag-coating increased several times from ca. $4 \mathrm{~nm}$ to $27 \mathrm{~nm}$. In turn, the roughness of modified PC with Ag thin film after the scratch test remained the same. In this case the modified polymer also exhibited better scratch resistance than the unmodified one. Moreover, scratches were clearly visible 
(a)

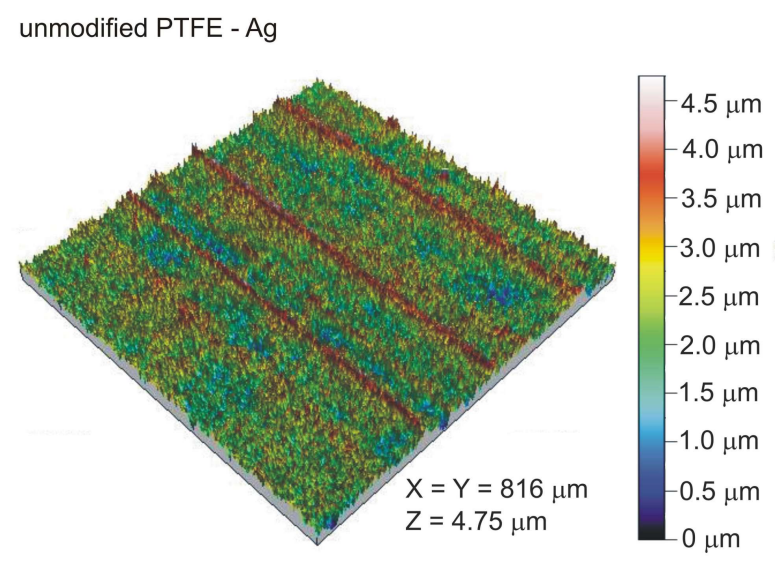

(b)

unmodified PC - Ag

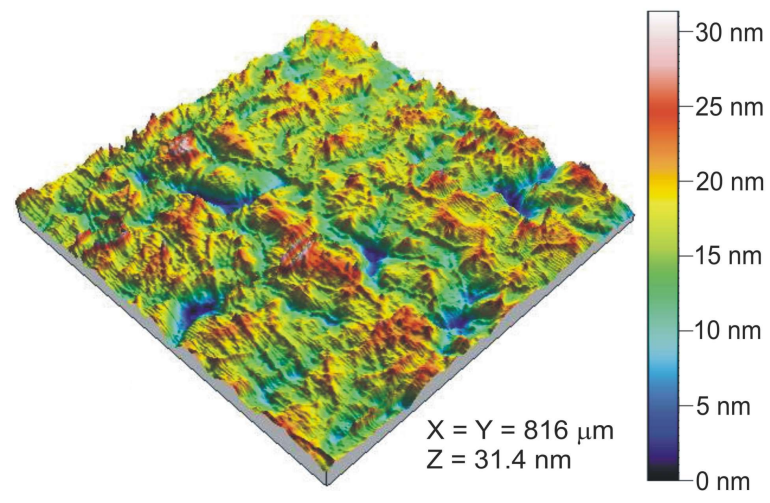

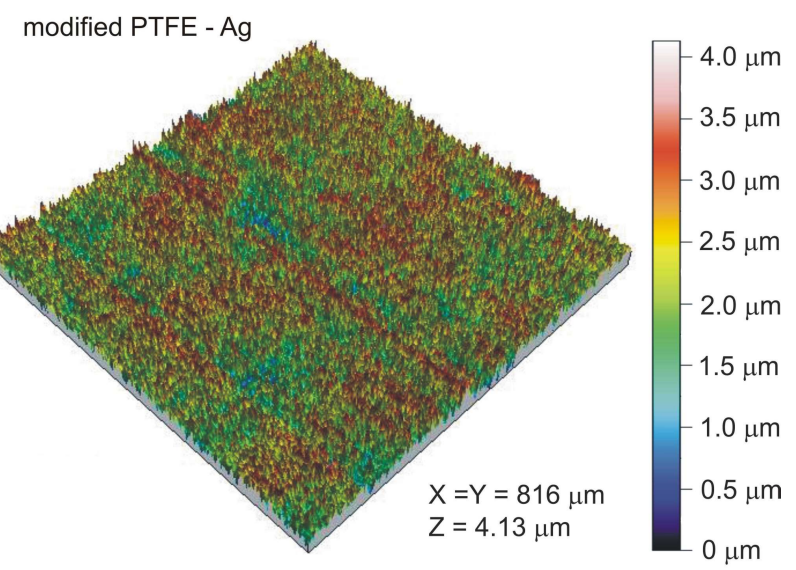

modified PC - Ag

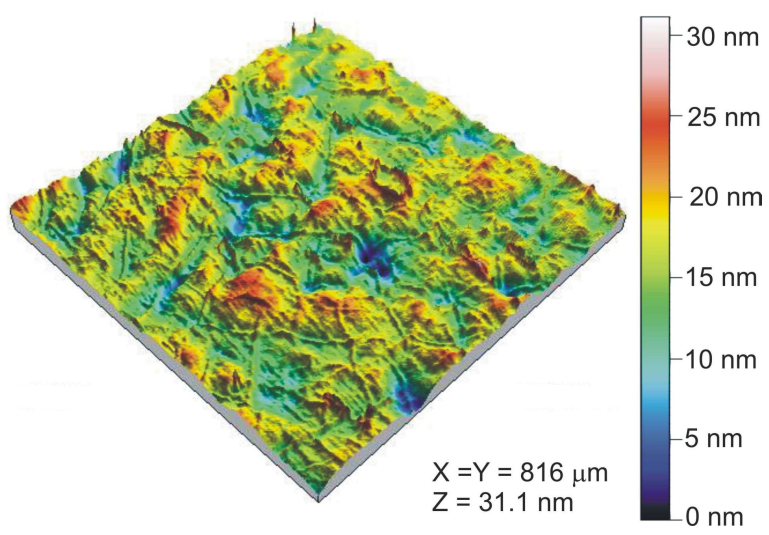

Fig. 4. Three dimensional surface images of unmodified and modified: (a) PTFE and (b) PC substrates with Ag coatings.

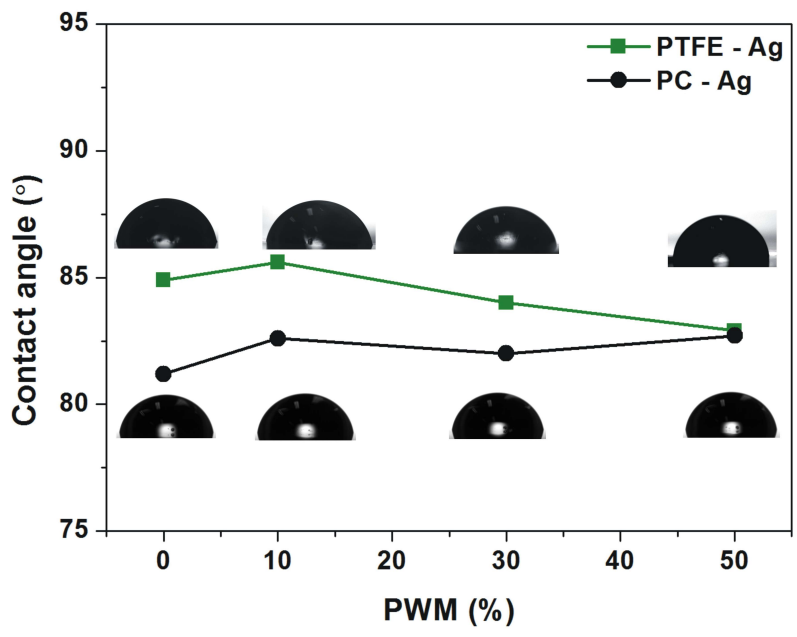

Fig. 5. Results of water contact angle measurements of PTFE and PC substrates with Ag thin film in the function of PWM coefficient. in the three-dimensional surface image of the investigated Ag coating deposited on plasma modified PC. Quantitative analysis of obtained images showed that the percentage of scratched off silver thin film from untreated PC substrate was almost three times higher than that of plasma treated. The scratched off $\mathrm{Ag}$ thin film for untreated and treated PC was equal to ca. $7.5 \%$ and $2.8 \%$, respectively. Argon plasma treatment seems to improve adhesion between polymer surface and also enhances the scratch resistance of the prepared thin film coatings.

The cross-section topographies of untreated and plasma treated Ag-coated PTFE and PC substrates are shown in Fig. 8. In case of PTFE substrate there was no significant change of cross-section topography between the treated 
(a)
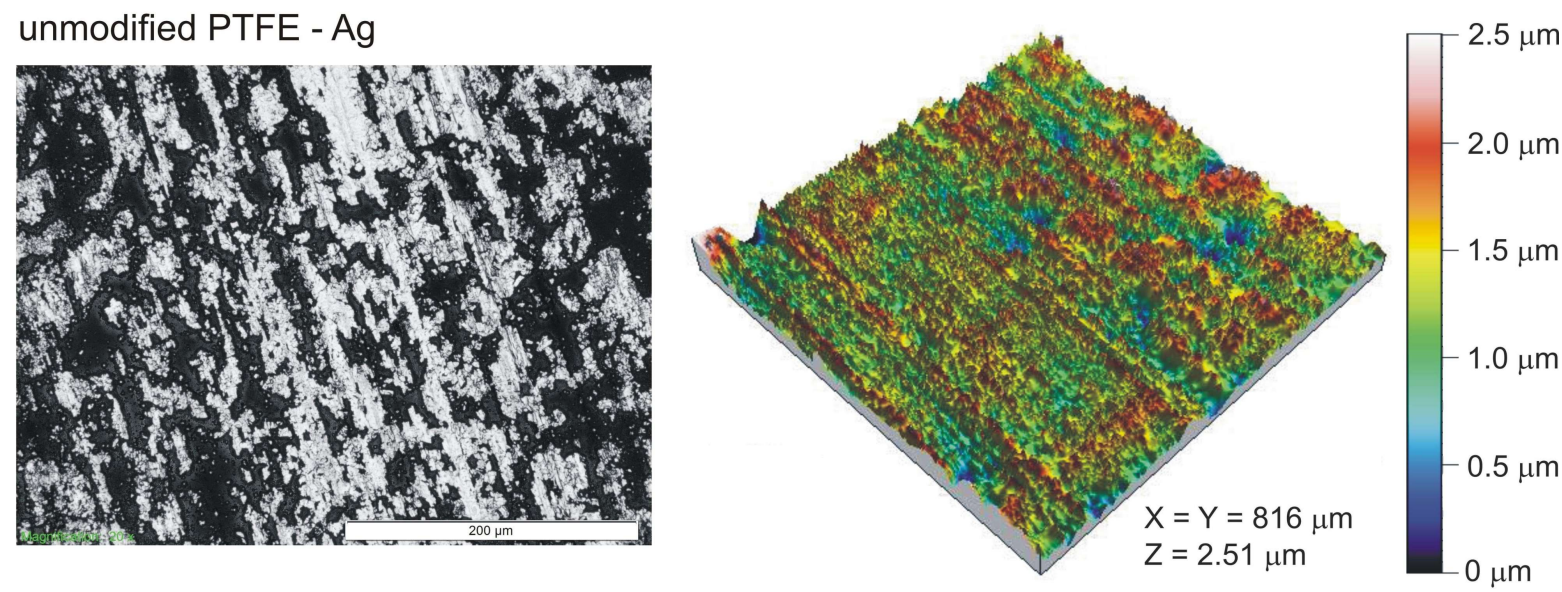

(b)
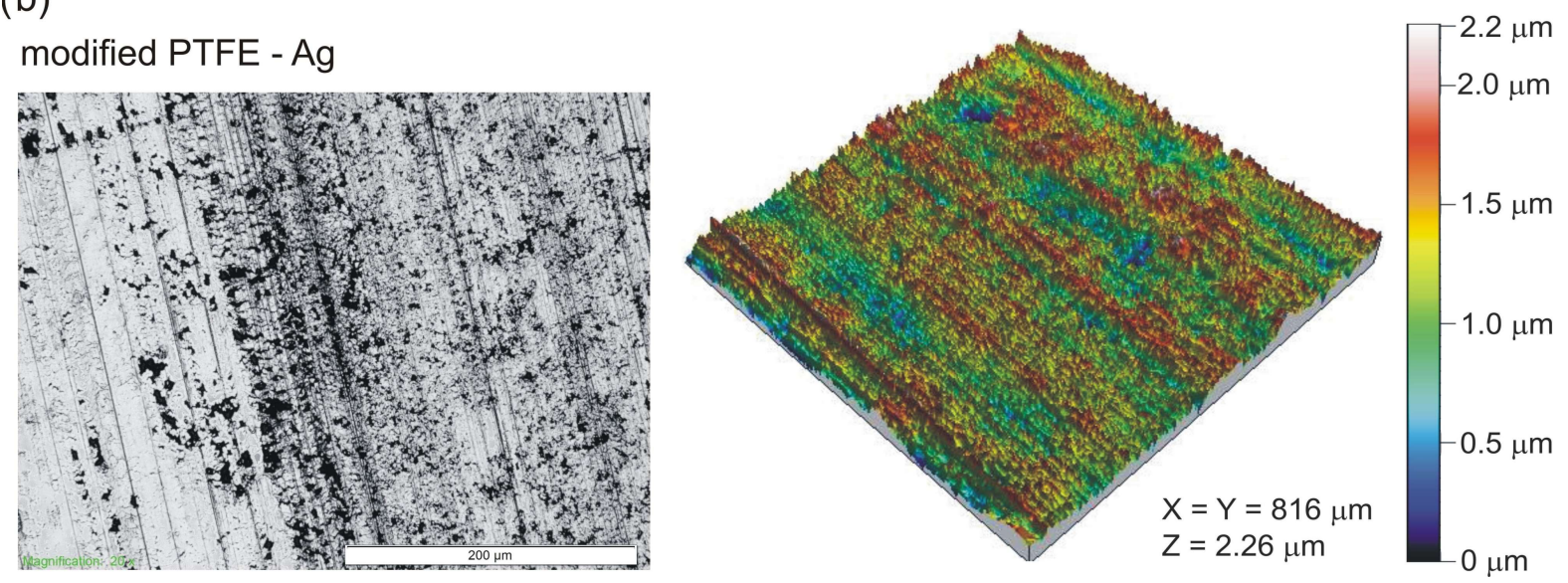

Fig. 6. Results of scratch test of PTFE with Ag coatings deposited on (a) unmodified and (b) modified polymer substrate.

and untreated PTFE substrate coated with Ag thin film. This may be caused by very rough surface of PTFE whose root mean square roughness $(\mathrm{Sq})$ was equal to ca. $700 \mathrm{~nm}$. Furthermore, the thickness of $\mathrm{Ag}$ coating was $50 \mathrm{~nm}$ and therefore the change of surface cross-section after the scratch test could be only slightly visible. Moreover, the images obtained from optical microscope confirmed that for untreated PTFE most of the Ag thin film was scratched off from the surface. In case of plasma treated PC substrate coated with Ag the scratches were shallow, hardly visible and only the negligible scuffing was observed. In turn, for the untreated Ag-coated PC substrate several deep scratches with the height of ca. $320 \mathrm{~nm}$ were observed, which revealed that not only $\mathrm{Ag}$ thin film, but also
PC substrate was scratched. Therefore, it can be assumed that the plasma treated substrate had advantageous influence on scratch resistance of the PC substrate coated with Ag thin film.

\section{Conclusions}

In this work the influence of argon plasma treatment on PTFE and PC surface properties and Ag coatings deposited by electron beam evaporation on unmodified and modified polymers were described. Analysis of contact angle measurements showed that surface wettability of PTFE and PC after argon plasma treatment with different powers was changed. The value of contact angle for deionized water decreased of about $40 \%$ and $25 \%$ for 
(a)

unmodified PC - Ag

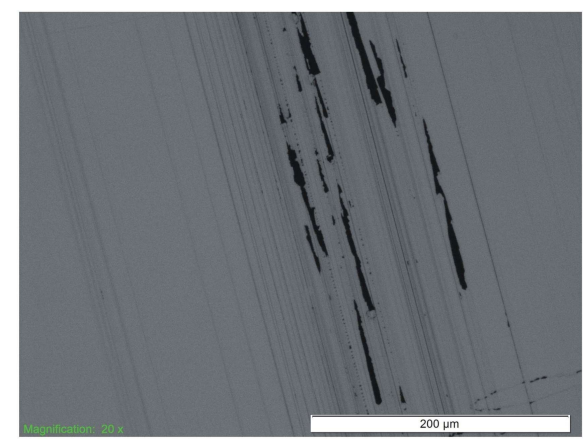

(b)

$$
\text { modified PC - Ag }
$$

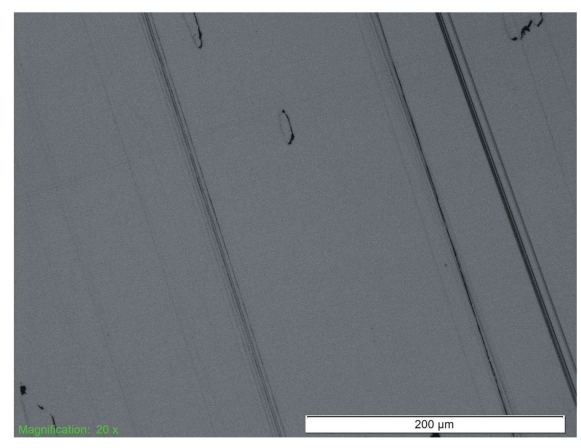

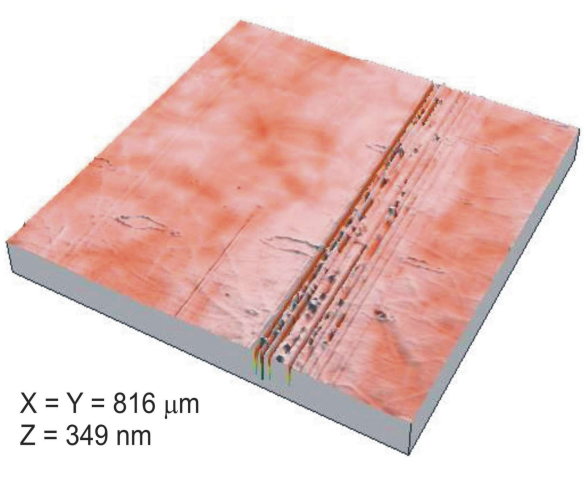

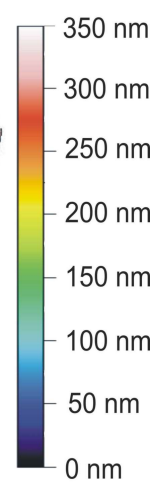

$0 \mathrm{~nm}$

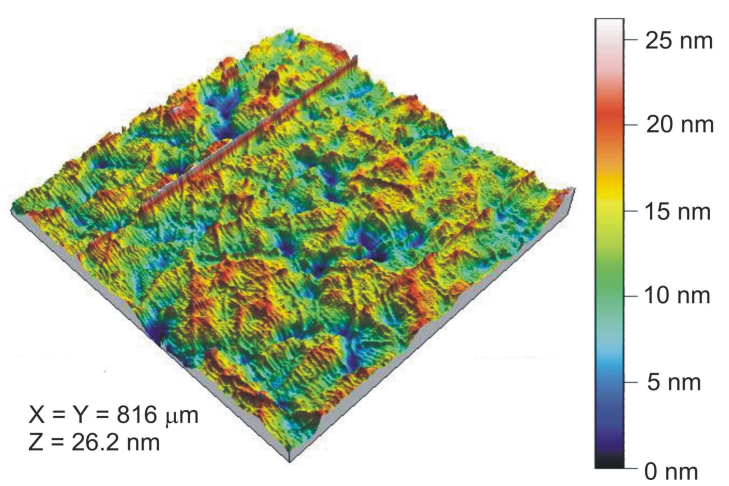

Fig. 7. Results of scratch test of PC with Ag coatings deposited on (a) unmodified and (b) modified polymer substrates.
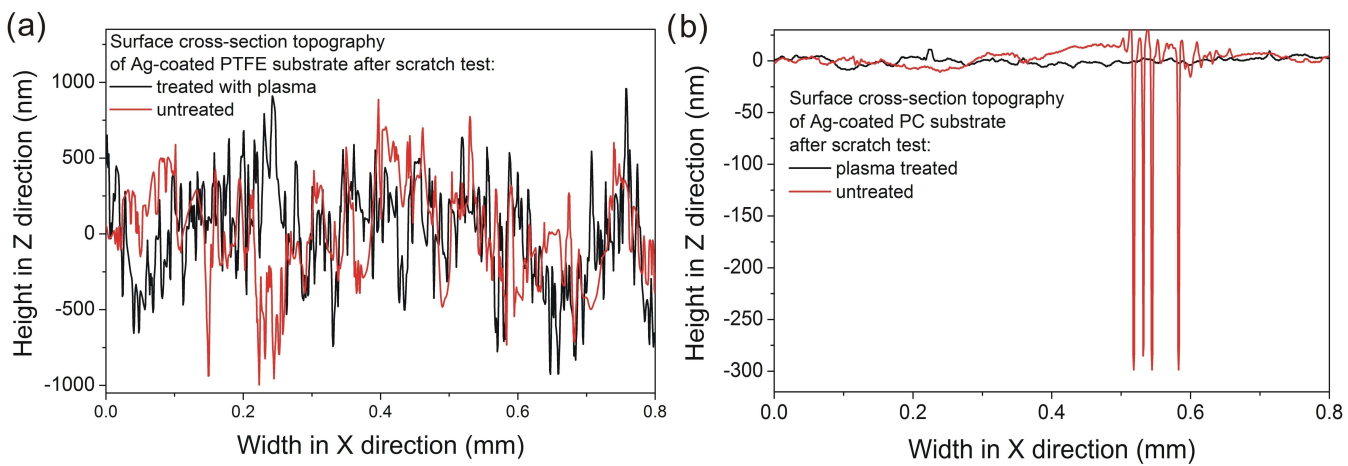

Fig. 8. Surface cross-section topography results after scratch test of untreated and plasma treated Ag-coated: (a) PTFE and (b) PC substrate.

polytetrafluoroethylene and polycarbonate surface, the modified polymers exhibited good scratch rerespectively. The ageing effect was not observed. sistance compared to the coatings on unmodified After 14 days the hydrophilic properties of poly- substrates. Plasma modification increased wettabilmer surfaces after argon plasma treatment were ity and improved adhesion between the polymer still observed. Moreover, Ag thin film deposited on surface and Ag coating and thus, it was possible 
to obtain good thin film scratch resistance of the prepared coatings. Such results show that metallic coatings deposited on plasma modified polymers are suitable for innovative application in, e.g., flexible electronics technology.

\section{Acknowledgements}

This work was co-financed by the Polish National Science Centre NCN in the years 2013 - 2016 as a Research Project Number DEC-2012/07/B/ST8/03760.

\section{References}

[1] Jacobs T., Morent R., De Geyter N., Leys C., J. Phys., 275 (2011), 1.

[2] Khaleel K.I., Jasim A.S., Ahmed M.A. K., VijaY Y.K., SRIVAStaVA S., Int. J. Rec. Res. Rev., 3 (2012), 1.

[3] Chan C.M., Ko T. M., HiRaoka H., Surf. Sci. Rep., 24 (1996), 1.

[4] Theodorakos I., Zacharatos F., Geremia R., Karnakis D., Zergioti I., Appl. Surf. Sci., 336 (2015), 157.

[5] Rezaei F., Shokri B., Sharifian M., Appl. Surf. Sci., 164 (2015), 471.

[6] Kim K.N., LeE S.M., Mishra A., Yeom G.Y., Thin Solid Films, 598 (2015), 315.

[7] JUNKAR I., Vacuum, 98 (2013), 111.

[8] Hegemann D., Brunner H., Oehr C., Nucl. Instr. Meth. B, 208 (2003), 281.

[9] Peyrouxa J., Duboisa M., Tomasellaa E., Petita E., Flahaut D., Appl. Surf. Sci., 315 (2014), 426.

[10] Vesel A., Mozetic M., Vacuum, 86 (2012), 634.

[11] Pelagade S., Singh N.L., Shah S., Qureshi A., RANe R.S., MukherJeE S., DeshPande U.P., Ganesan V., Shripathi T., J. Phys., 208 (2010), 1.

[12] Kolska Z., ReZnickova A., Hnatowicz V., SVORCIK V., Vacuum, 86 (2012), 643.

[13] Kotal V., Svorcik V., Slepicka P., Sajdl P., Blahova O., Sutta P., Hnatowicz V., Plasma Process. Polym., 4 (2007), 69.

[14] Bismarck A., Brostow W., Chiu R., Lobland H.E., Ho K.K.C., Polym. Eng. Sci., (2008), 1971.

[15] VAndencasteele N., Reniers F., J. Electron Spectrosc., 178 - 179 (2010), 394.

[16] Tendero C., Tixier C., Tristant P., DesmaiSON J., LEPRINCE P., Spectrochim. Acta B, 61 (2006), 2.
[17] Bardos L., Barankowva H., Thin Solid Films, 518 (2010), 6705.

[18] Deynse van A., Cools P., Leys C., Morent R., GEYTER DE N., Surf. Coat. Tech., 258 (2014), 359.

[19] Yoshida S., Hagiwara K., Hasebe T., Hotta A., Surf. Coat. Tech., 233 (2013), 99.

[20] Junkar I., Vesel A., Cvelbar U., Mozetic M., STRAND S., Vacuum, 84 (2010), 83.

[21] Hunke H., Soin N., Gebhard A., Shah T., Kramer E., WitAN K., NARASIMUlu A.A., Siores E., Wear, 338 - 339 (2015), 122.

[22] Borcia C., Punga I.L., Borcia G., Appl. Surf. Sci., 317 (2014), 103

[23] Slepicka P., Mala Z., Rimpelova S., Slepickova KaSAlKova N., SVORCIK V., React. Funct. Polym., 95 (2015), 71

[24] Bormashenko E., Whyman G., Multanen V., Sulzinger E., Chaniel G., J. Colloid Interf. Sci., 448 (2015), 175

[25] Slepicka P., VASINA A., Kolska Z., LUXBACHER T., MALINSKY P., MACKOVA A., SVORCIK V., Nucl. Instr. Meth. B, 268 (2010), 2111.

[26] Trepilowski K., Rymuszka D., Holysz L., CHIBOWSKI E., Ariel. Ac. Il, (2014), 155.

[27] Jokinen V., Suvanto P., Franssila S., Biomicrofluidics, 6 (2012), 016501-1.

[28] Zhou X. L., Chen A. F., Liu J. C., Wu X. K., Zhang J. S., Surf. Coat. Tech., 206 (2011), 132.

[29] Kwok D. Y., Neumann A. W., Adv. Colloid Interfac., 81 (1999), 167.

[30] Wojcieszak D., Kaczmarek D., Antosiak A., MaZUR M., RYbaK Z., Rusak A., OSĘKOWSKa M., PoniedzialeK A., Gamian A., SzPonar B., Mat. Sci. Eng. C-Mater., 56 (2015), 48.

[31] ISO/TC 172/S9C 7/WG 3N30 Standard, Spectacle Lenses: Test Method for Abrasion Resistance, 1998.

[32] Mazur M., SzymańsKa M., KaczmareK D., KALISZ M., WOJCIESZAK D., DOMARADZKI J., PlaCIDO F., Appl. Surf. Sci., 301 (2014), 63.

[33] SARAni A., Geyter DE N., Nikifrov A.Y., Morent R., Leys C., Hubert J., Reniers F., Surf. Coat. Tech., 206 (2012), 2226.

[34] Wang C., Chen J.R., Appl. Surf. Sci., 253 (2007), 4599 .

Received 2015-11-24 Accepted 2016-04-27 